\title{
Management of acute diarrhoea with low osmolarity oral rehydration solutions and Lactobacillus strain GG
}

\author{
T Rautanen, E Isolauri, E Salo, T Vesikari
}

\begin{abstract}
Two hypotonic oral rehydration solutions with osmolarities of $224 \mathrm{mosmol} / 1 \mathrm{Na}^{+}$ $60 \mathrm{mmol} / 1$, glucose $84 \mathrm{mmol} / \mathrm{l})$ and $204 \mathrm{mosmol} / 1 \quad\left(\mathrm{Na}^{+} 60 \mathrm{mmol} / 1\right.$, glucose $64 \mathrm{mmol} / \mathrm{l})$, respectively, and oral treatment with Lactobacillus GG were evaluated in a double blind trial in children aged 6-36 months hospitalised for acute diarrhoea. Early administration of Lactobacillus GG at the start of oral rehydration resulted in the shortest duration of diarrhoea, best weight gain, and fastest correction of acidosis. A reduced osmolarity oral rehydration solution (224 mosmol/1) combined with early administration of Lactobacillus GG is an effective treatment for acute diarrhoea in young children; further reduction of osmolarity may not be beneficial.

(Arch Dis Child 1998;79:157-160)
\end{abstract}

Keywords: diarrhoea; oral rehydration; reduced osmolarity; Lactobacillus GG

Comprehensive management of acute diarrhoea in children consists of oral rehydration, appropriate nutritional treatment, and various auxiliary treatments aimed at shortening the diarrhoeal episode. ${ }^{1-5}$ All these components of treatment may contribute to correction of dehydration, better weight gain, and the reduction of both watery stools and the duration of diarrhoea.

Hypotonic oral rehydration solution with an

Department of Paediatrics, Jorvi Hospital, Turuntie 150, FIN 02740 Espoo, Finland

T Rautanen

Department of Paediatrics, University of Turku, Turku, Finland

E Isolauri

Department of Paediatrics, Helsinki University Hospital, Helsinki, Finland

E Salo

University of Tampere, Medical School, Tampere, Finland $\mathrm{T}$ Vesikari

Correspondence to: Dr Rautanen.

Accepted 9 March 1998 ined whether immediate administration of Lactobacillus GG at the time of initiation of oral
Lactobacillus strain GG, ATCC 53103, has been shown to shorten the duration of acute diarrhoea, ${ }^{4}{ }^{514} 15$ and to reduce the duration of rotavirus excretion in diarrhoea ${ }^{15}$; therefore, it can be regarded as a promising auxiliary treatment of acute diarrhoea in children. We exam- rehydration treatment results in further benefit compared with its administration after initial oral rehydration, at the time of resumed feeding.

\section{Patients and methods}

The study was carried out at the Aurora Hospital, Helsinki. The study protocol was approved by the ethics review committee of the Health Care Centre of Helsinki. Parents were given verbal and written information about the study before a written witnessed consent was obtained for the enrolment of their child in the study.

Altogether, 123 children aged 6-36 months, suffering from acute diarrhoea (duration less than seven days) and needing hospitalisation, were included in the study. Rotavirus was detected in the stools of $113(92 \%)$ of the children. Patients with a serum sodium concentration above 155 or below $130 \mathrm{mmol} / \mathrm{l}$ were excluded (only one patient). Furthermore, five patients who were enrolled but required intravenous rehydration were excluded from analysis.

Alternate children received an oral rehydration solution with either an osmolarity of $224 \mathrm{mosmol} / 1$ (hypotonic oral rehydration solution) or $204 \mathrm{mosmol} / 1$ (ultrahypotonic oral rehydration solution). Table 1 gives the molar compositions of the two solutions. The solutions were prepared by the central pharmacy of Helsinki City Hospitals, and supplied as a dry powder, which was dissolved in $500 \mathrm{ml}$ of water on the ward. The sachets containing the powder and the two solutions after reconstitution were identical in appearance. The oral rehydration solutions were labelled as solutions I and II. Only the pharmacy personnel knew the code for the solutions during the study.

In addition to the oral rehydration solution treatment, patients were randomised to receive Lactobacillus GG or placebo powder twice a day during the hospital stay. The Lactobacillus GG was provided in $1.25 \mathrm{~g}$ freeze dried doses in small plastic bags containing $5 \times 10^{9}$ colony forming units/dose and stored at $-18^{\circ} \mathrm{C}$. The placebo powder was microcrystalline cellulose

Table 1 Composition of the hypotonic and ultrahypotonic oral rehydration solution used in the study

\begin{tabular}{lcc}
\hline & Hypotonic & Ultrahypotonic \\
\hline Sodium $(\mathrm{mmol} / \mathrm{l})$ & 60 & 60 \\
Potassium $(\mathrm{mmol} / \mathrm{l})$ & 20 & 20 \\
Chloride $(\mathrm{mmol} / \mathrm{l})$ & 50 & 50 \\
Glucose $(\mathrm{mmol} / \mathrm{l})$ & 84 & 64 \\
Citrate $(\mathrm{mmol} / \mathrm{l})$ & 10 & 10 \\
Total osmolarity (mosmol/l) & 224 & 204 \\
\hline
\end{tabular}


Table 2 Patient groups

\begin{tabular}{lll}
\hline Group & $\begin{array}{l}\text { First dose during initial } \\
\text { rehydration }\end{array}$ & $\begin{array}{l}\text { Following doses during } \\
\text { hospital stay }\end{array}$ \\
\hline 1 & Sachet A & Sachet A \\
2 & Sachet A & Sachet B \\
3 & Sachet B & Sachet A \\
4 & Sachet B & Sachet B \\
\hline
\end{tabular}

(Ph. Eur. 2nd ed. II). The Lactobacillus GG and placebo bags and powders were identical in appearance. The freeze dried powders were mixed with $5 \mathrm{ml}$ of water and given by spoon or a nasogastric tube. These powder sachets were packed and supplied by Valio Ltd (Helsinki, Finland). Sachets were labelled with codes A and B: A contained Lactobacillus GG and B contained placebo. Patients were randomised to one of four different treatment groups (table 2).

In this way, patients received either one early Lactobacillus GG dose only, Lactobacillus GG twice a day throughout the hospital stay, Lactobacillus GG during the maintenance phase only, or placebo only.

The oral rehydration solution was prescribed according to the patient's degree of dehydration. This was assessed by the physician in the emergency ward by calculating the acute weight loss against premorbidity weight or according to clinical signs of dehydration. It was recommended that four thirds of the estimated fluid deficit was given during the first six to eight hours. If necessary, the solution was given through a nasogastric drip. After the first six to eight hours of rehydration, the children were given additional oral rehydration solution to the volume of the diarrhoeal stools and vomits lost, estimated by the physician and nurses in the ward. Normal feeding for age was resumed immediately after the six to eight hour rehydration period. Fermented milk products

Table 3 Characteristics of the patients on admission according to oral rehydration solution (ORS) given

\begin{tabular}{|c|c|c|}
\hline & $\begin{array}{l}\text { Hypotonic ORS } \\
(n=59)\end{array}$ & $\begin{array}{l}\text { Ultrahypotonic ORS } \\
(n=64)\end{array}$ \\
\hline \multicolumn{3}{|l|}{ Admission } \\
\hline Patients (\%) with rotavirus & $56(95 \%)$ & $57(89 \%)$ \\
\hline Age (months) & $17.0(14.9$ to 18.3$)$ & $18.0(16.2$ to 20.6$)$ \\
\hline \multicolumn{3}{|l|}{ Duration of diarrhoea before admission } \\
\hline Acute weight loss (g) & $463(431$ to 496$)$ & $462(417$ to 506$)$ \\
\hline Admission weight $(\mathrm{kg})$ & $10.1(9.7$ to 10.5$)$ & $10.6(10.0$ to 11.2$)$ \\
\hline Blood sodium concentration $(\mathrm{mmol} / \mathrm{l})$ & $137(136$ to 138$)$ & $137(136$ to 137$)$ \\
\hline Blood potassium concentration $(\mathrm{mmol} / \mathrm{l})$ & $4.1(4.0$ to 4.3$)$ & $4.2(4.1$ to 4.3$)$ \\
\hline Blood base excess $(\mathrm{mmol} / \mathrm{l})$ & $-7.6(-8.6$, to 6.7$)$ & $-6.7(-7.6$, to 5.8$)$ \\
\hline Bacteriotherapy & & \\
\hline $\begin{array}{l}\text { Patients (\%) with early LGG treatment } \\
\text { Rehydration treatment }\end{array}$ & $31(53 \%)$ & $30(47 \%)$ \\
\hline Initial rehydration $(\mathrm{ml})$ & $631(587$ to 675$)$ & $614(576$ to 652$)$ \\
\hline Total consumption of ORS (ml) & $1388(1211$ to 1564$)$ & $1356(1216$ to 1495$)$ \\
\hline
\end{tabular}

Values are mean $(95 \%$ confidence intervals) except where stated.

Differences between the groups were not significant.

LGG, Lactobacillus strain GG.

Table 4 Effect of type of oral rehydration solution (ORS) and early dose of Lactobacillus strain $G G(L G G)$ on duration of diarrhoea in the hospital (hours)

\begin{tabular}{lll}
\hline & Hypotonic ORS & Ultrahypotonic ORS \\
\hline Early dose of LGG & $17.7(12.2$ to 25.6$)$ & $29.5(23.2$ to 37.7$)$ \\
No early dose of LGG & $30.4(23.6$ to 39.3$)$ & $30.4(24.8$ to 37.2) \\
\hline
\end{tabular}

Values are mean $(95 \%$ confidence intervals)

ANOvA: effect of ORS, $\mathrm{F}=3.79, \mathrm{p}=0.05$; effect of LGG, $\mathrm{F}=4.78, \mathrm{p}=0.03$; interaction, $\mathrm{F}=3.88$, $\mathrm{p}=0.05$. were excluded from the diet to prevent interference in the dietary intervention.

The exact amount of oral rehydration solution consumed was recorded by the ward nurses. They also recorded the number and quality of the stools passed by the children (characterised as watery, loose, or solid) and vomiting episodes. Weight was measured on admission, after initial rehydration, and daily thereafter during the hospital stay. Blood sodium and potassium concentrations and acid-base balance were determined on admission and daily thereafter. A stool sample was taken during the hospital stay for the detection of rotavirus, using an enzyme immunoassay (Rotazyme; Dako, Glostrup, Denmark).

The analysis of variance (including two factor ANOVA and ANOVA for repeated measures) was used in statistical comparisons. Natural logarithmic transformation was used when appropriate because of skewed distribution.

\section{Results}

ORAL REHYDRATION

Of the 123 patients, 59 received hypotonic oral rehydration solution and 64 received ultrahypotonic oral rehydration solution. The two oral rehydration solution groups did not differ for the presence of rotavirus. The number of patients receiving early Lactobacillus GG treatment was similar in both oral rehydration solution groups (table 3 ). The age of the patients and the clinical picture on admission were comparable in both oral rehydration solution groups (table 3). The consumption of oral rehydration solution was similar in both groups (table 3). The blood sodium and potassium concentrations remained similar in both oral rehydration solution groups during the whole hospital stay (ANOva for repeated measures).

\section{BACTERIOTHERAPY}

Of the 123 patients, 61 received early Lactobacillus GG treatment during rehydration. Of these, 28 received one single dose and 33 continued to receive Lactobacillus GG twice a day during the whole hospital stay. Of the remaining 62 patients, 32 received an initial dose of placebo, and thereafter Lactobacillus GG, and 30 received only placebo throughout the hospital stay.

OUTCOME OF PATIENTS

Both early Lactobacillus GG treatment and hypotonic oral rehydration solution had an independent effect on the duration of diarrhoea (table 4). ANOVA demonstrated that there was a significant interaction between the two interventions. The mean duration of diarrhoea in the subgroup receiving early Lactobacillus GG together with the hypotonic oral rehydration solutions was 17.7 hours (95\% CI, 12.2 to 25.6), significantly shorter than the other subgroups (table 4). There was no difference between the groups receiving early or late Lactobacillus GG with either type of oral rehydration solution in the number of stools passed in hospital (which was between seven and eight in all groups). 
The best weight gain during rehydration was achieved in the group receiving hypotonic oral rehydration solution and early Lactobacillus GG treatment, in which the mean weight gain was $262 \mathrm{~g}$ (95\% CI, 170 to 355$)$. In the group receiving the ultrahypotonic oral rehydration solution without early Lactobacillus GG, the mean weight gain was $127 \mathrm{~g}$ (95\% CI, 27 to 227). The hypotonic oral rehydration solution rather than early Lactobacillus GG treatment was responsible for weight gain during rehydration $(\mathrm{F}=3.76, \mathrm{p}=0.06 ; \mathrm{F}=1.11, \mathrm{p}=0.29$, respectively); no interaction between the two interventions was seen in this respect.

The best recovery from acidosis was also seen in the group receiving the hypotonic oral rehydration solution and early Lactobacillus GG, but the differences were not significant. The mean base excess after rehydration was $-2.8 \mathrm{mmol} / \mathrm{l}$ in this group, higher than in any other treatment group.

\section{Discussion}

Our previous studies showed that a hypotonic oral rehydration solution with an osmolarity of $224 \mathrm{mosmol} / \mathrm{l}$ performs better than an isotonic oral rehydration solution. ${ }^{67}$ In the present study, we wanted to find out whether a further reduction in osmolarity to $204 \mathrm{mosmol} / \mathrm{l}$ and of glucose content to $64 \mathrm{mmol} / 1$ would improve the rehydrating properties of the oral rehydration solution still further. Both hypotonic oral rehydration solutions were effective for treatment of dehydration. However, there was a small difference in favour of the solution with an osmolarity of $224 \mathrm{mosmol} / \mathrm{l}$, which was better in correcting weight loss and acidosis, and was associated with a slightly shorter duration of diarrhoea. Probably, both solutions contained a sufficiently low concentration of glucose not to provoke osmotic diarrhoea. The oral rehydration solution with the higher glucose content might have resulted in faster recovery from acidosis and cessation of diarrhoea because of a greater glucose enhanced sodium and water uptake in the small intestine.

Using healthy rats, Wapnir et al compared several oral rehydration solutions with osmolarities from 155 to $330 \mathrm{mosmol} / \mathrm{l}$ and different sodium and glucose contents. The maximum water absorption was seen for solutions with very low osmolarity (155-220 mosmol/l) and glucose content $(30 \mathrm{mmol} / \mathrm{l})$. However, a slight increase of the glucose content $(45-111 \mathrm{mmol} / \mathrm{l})$ resulted in higher sodium uptake, although the sodium concentrations stayed constant. ${ }^{12}$ Farthing recommended that the sodium concentration should be $\sim 60 \mathrm{mmol} / \mathrm{l}$ and the glucose content between 50 and $100 \mathrm{mmol} / \mathrm{l}$ to ensure optimal water and sodium absorption, based on studies with cholera toxin treated rat small intestine and rotavirus infected neonatal rats. ${ }^{9}$

Clinical studies of children with diarrhoea have compared various hypotonic solutions with the oral rehydration solution recommended by the WHO (osmolarity $311 \mathrm{mosmol} / \mathrm{l}$, sodium $90 \mathrm{mmol} / \mathrm{l}$, glucose $111 \mathrm{mmol} / \mathrm{l})$. Solutions with osmolarities of $249 \mathrm{mosmol} / \mathrm{l}$ (sodium $60 \mathrm{mmol} / \mathrm{l}$, glucose $89 \mathrm{mmol} / \mathrm{l}$ ), $224 \mathrm{mosmol} / 1$ (sodium $60 \mathrm{mmol} / \mathrm{l}$, glucose $84 \mathrm{mmol} / \mathrm{l}$ ), and $210 \mathrm{mosmol} / 1$ (sodium $60 \mathrm{mmol} / \mathrm{l}$, glucose $75 \mathrm{mmol} / \mathrm{l}$ ) have been investigated. ${ }^{16-18}$ In all studies, the hypotonic solutions performed better than standard oral rehydration solutions, although in a study in Bangladesh the hypotonic solution (249 mosmol/l) was beneficial only in rotavirus negative patients. ${ }^{16}$ In contrast, in our previous study a hypotonic oral rehydration solution with osmolarity of $224 \mathrm{mosmol} / 1$ performed well in rotavirus positive patients, ${ }^{7}$ a finding confirmed in the present study.

As seen in earlier studies in Tampere and elsewhere, ${ }^{4} 51415$ Lactobacillus GG significantly shortened the duration of diarrhoea. Guarino et al found that administration of Lactobacillus GG also significantly shortened the excretion of rotavirus in acute diarrhoea..$^{15}$ Our study shows that to reach maximal effect, Lactobacillus GG should be given as early as possible. The results suggest that a single early dose of Lactobacillus GG might be sufficient, because further doses during the maintenance phase did not improve the outcome. Theoretically, a single dose of Lactobacillus GG could result in sufficient colonisation, which might be maintained for up to seven days after ingestion. ${ }^{19}$

Recently, it has been suggested that rotavirus infection gives rise to a biphasic diarrhoeal illness, first causing an osmotic diarrhoea and later overgrowth of urease producing bacteria. ${ }^{20}$ Rotavirus infection causes patchy lesions in the small intestine mucosa. ${ }^{21}$ This leads to reduced absorptive properties and malabsorption of carbohydrate, ${ }^{22}$ and to osmotic diarrhoea, which turns the colonic contents acidic. ${ }^{23}$ The acidic stools convert ammonia to ammonium ions, which are poorly absorbed from the colon. ${ }^{24}$ Unabsorbed ammonium ions provide nitrogen to many enteric bacteria, including urease producing bacteria. ${ }^{25}$ Overgrowth of urease producing bacteria might predispose to further mucosal damage, initiated by rotavirus infection. ${ }^{2526}$ Following this hypothesis, an intervention that reduces ammonia content or bacterial overgrowth in the intestine could decrease the severity of rotavirus infection. Oral administration of lactobacilli has been identified as such an intervention..$^{20}$ In addition, hypotonic oral rehydration solutions prevent osmotic diarrhoea and acidification of the stools, ${ }^{7}$ which might also reduce bacterial overgrowth and prevent the second phase of rotavirus infection. This could explain the positive interaction between the Lactobacillus GG treatment and the hypotonic oral rehydration solution.

Based on these findings, we conclude that both Lactobacillus GG and hypotonic oral rehydration solutions are safe and effective treatments of acute diarrhoea and seem to have a positive interaction. For optimal effect, we suggest that Lactobacillus GG should be given with the oral rehydration solution during initial rehydration.

The authors thank the nursing staff of the paediatric emergency ward and infectious diseases ward of Aurora Hospital for their dedication to this trial. 
1 World Health Organisation. A manual for the treatment of acute diarrhoea for use by physicians and other senior health workers. Document WHO/CDD/SER 80.2 Rev. 2. Geneva: WHO, 1990

2 Isolauri E, Vesikari T. Oral rehydration, rapid feeding, and cholestyramine for treatment of acute diarrhoea. $\mathcal{F}$ Pediatr Gastroenterol Nutr 1985;4:366-74.

3 Isolauri E, Vesikari T, Saha P, Viander M. Milk versus no milk in rapid refeeding after acute gastroenteritis. $\mathcal{F}$ Pediat Gastroenterol Nutr 1986;5:254-61.

4 Isolauri E, Juntunen M, Rautanen T, Sillanaukee P, Koivula T. A human Lactobacillus strain (Lactobacillus GG) promotes recovery from acute diarrhea in children. Pediatrics 1991;88:90-7.

5 Majamaa $H$, Isolauri E, Saxelin M, Vesikari T. Lactic acid bacteria in the treatment of acute rotavirus gastroenteritis. 7 Pediatr Gastroenterol Nutr 1995;20:333-8.

6 Rautanen T, El-Radhi S, Vesikari T. Clinical experience with a hypotonic oral rehydration solution in acute diarrhoea. Acta Paediatr 1993;82:52-4.

7 Rautanen T, Kurki S, Vesikari T. Randomised double blind study of hypotonic oral rehydration solution in diarrhoea. study of hypotonic oral rehydrati
Arch Dis Child 1997;76:272-4.

Arch Dis Child 1997;76:272-4.
8 Sandhu BK, Christobal FL, Brueton MJ. Optimising oral rehydration solution composition in model systems: studies in normal mammalian small intestine. Acta Paediatr Scand Suppl 1989;364:17-22.

9 Farthing MJG. Disease-related animal models for optimising oral rehydration solution composition. Acta Paediat Scand Suppl 1989;364:23-30.

10 Hunt JB, Thillainayagum AV, Salim AFM, Carnaby S, Elliott EJ, Farthing MJG. Water and solute absorption from a new hypotonic oral rehydration solution: evaluation in human and animal perfusion models. Gut 1992:33:1652-9.

11 Cunha Ferreira RCM, Elliott EJ, Watson AJM, Brennan E, Walker-Smith JA, Farthing MJG. Dominant role for osmolality in the efficacy of glucose and glycine-containing oral rehydration solutions: studies in a rat model of secretory rehydration solutions: studies in a rat

diarrhoea. Acta Paediatr 1992;81:46-50.
12 Wapnir RA, Lifshitz F. Osmolality and solute concentration - their relationship with oral hydration soluconcentration - their relationship with oral hydration solution effectivenes:

13 Hunt JB, Elliott EJ, Fairclough PD, Clark ML, Farthing MJG. Water and solute absorption from hypotonic glucose-electrolyte solutions in human jejunum. Gut 1992 33:479-83.
14 Kaila M, Isolauri E, Soppi E, Laine S, Arvilommi H. Enhancement of the circulating antibody secreting cell response in human diarrhoea by a human lactobacillus strain. Pediatr Res 1992;32:141-4.

15 Guarino A, Canani R, Spagnuolo M, Albano F, Di Benedetto L. Oral bacterial therapy reduces the duration of symptoms and of viral excretion in children with mild diarrhoea. 7 Pediatr Gastroenterol Nutr 1997;25:516-19.

16 Mahalanabis D, Faruque ASG, Hoque SS, Faruque SM. Hypotonic oral rehydration solution in acute diarrhoea: a controlled clinical trial. Acta Paediatr 1995;84:289-93.

17 Bhan MK, Chea Woo E, Fontaine O, Maulen-Radovan I, Pierce NF, Ribeiro Jr H. Multicentre evaluation of reduced-osmolarity oral rehydration salts solution. Lancet 1995;345:282-5.

18 El-Mougi M, El-Akkad N, Hendawi A, et al. Is a low-osmolarity ORS solution more efficacious than standard WHO ORS solution? F Pediatr Gastroenterol Nutr 1994; 19:83-6.

19 Goldin BR, Gorbach SL, Saxelin M, Barakat S, Gualtieri L, Salminen S. Survival of Lactobacillus species (strain GG) in human gastrointestinal tract. Dig Dis Sci 1992;37:121-8.

20 Isolauri E, Kaila M, Mykkänen H, Ling WH, Salminen S. Oral bacteriotherapy for viral gastroenteritis. Dig Dis $S c i$ 1994;39:2595-600.

21 Bishop RF, Davidson GP, Holmes IH, Ruck BJ. Virus particles in epithelial cells of duodenal mucosa from children with acute nonbacterial gastroenteritis. Lancet 1973;ii: 1281-3.

22 Sack DA, Rhoads M, Molla A, Molla AM, Wahed MA. Carbohydrate malabsorption in infants with rotavirus diarrhoea. Am f Clin Nutr 1982;36:1112-18.

23 Graham DY, Sackman JW, Estes MK. Pathogenesis of rotavirus-induced diarrhea. Preliminary studies in miniature swine piglet. Dig Dis Sci 1984;29:1028-35.

24 Cohen RM, Stephenson RL, Feldman GM. Bicarbonate secretion modulates ammonium absorption in rat distal colon in vivo. Am $\mathcal{F}$ Physiol 1988;254:F657-67.

25 Mobley HLT, Hausinger RP. Microbial ureases: significance, regulation, and molecular characterization. Microbiol Rev 1989;53:85-108.

$26 \mathrm{Xu} \mathrm{JK}$, Goodwin CS, Cooper M, Robinson J. Intracellular vacuolisation caused by the urease of $\mathrm{H}$ pylori. F Infect Dis 1990;161:1302-4. 